\title{
CO-METABOLISM OF DDT BY THE NEWLY ISOLATED BACTERIUM, PSEUDOXANTHOMONAS SP. WAX
}

\author{
Guangli Wang; Ji Zhang; Li Wang; Bin Liang; Kai Chen; Shunpeng Li; Jiandong Jiang*
}

Department of Microbiology, Key Lab of Microbiological Engineering of Agricultural Environment, Ministry of Agriculture, College of Life Sciences, Nanjing Agricultural University, 210095, Nanjing, Jiangsu Province, China

Submitted: April 17, 2009; Returned to authors for corrections: October 08, 2009; Approved: February 18, 2010.

\begin{abstract}
Microbial degradation of 1,1,1-trichloro-2,2-bis(p-chlorophenyl)ethane (DDT) is the most promising way to clean up DDT residues found in the environment. In this paper, a bacterium designated as wax, which was capable of co-metabolizing DDT with other carbon sources, was isolated from a long-term DDTcontaminated soil sample by an enrichment culture technique. The new isolate was identified as a member of the Pseudoxanthomonas sp., based on its morphological, physiological and biochemical properties, as well as by $16 \mathrm{~S}$ rRNA gene analysis. In the presence of $100 \mathrm{mg} \mathrm{l}^{-1}$ glucose, the wax strain could degrade over $95 \%$ of the total DDT, at a concentration of $20 \mathrm{mg} \mathrm{l}^{-1}$, in 72 hours, and could degrade over $60 \%$ of the total DDT, at a concentration of $100 \mathrm{mg} \mathrm{l}^{-1}$, in 144 hours. The wax strain had the highest degradation efficiency among all of the documented DDT-degrading bacteria. The wax strain could efficiently degrade DDT at temperatures ranging from 20 to $37^{\circ} \mathrm{C}$, and with initial $\mathrm{pH}$ values ranging from 7 to 9 . The bacterium could also simultaneously co-metabolize 1,1-dichloro-2,2-bis(p-chlorophenyl)ethane (DDD), 2,2-bis(p-chlorophenyl)-1,1-dichlorethylene (DDE), and other organochlorine compounds. The wax strain could also completely remove $20 \mathrm{mg} \mathrm{kg}^{-1}$ of DDT from both sterile and non-sterile soils in 20 days. This study demonstrates the significant potential use of Pseudoxanthomonas sp. wax for the bioremediation of DDT in the environment.
\end{abstract}

Key words: DDT, Co-metabolism, Bioremediation, Pseudoxanthomonas sp.

\section{INTRODUCTION}

DDT [1,1,1-trichloro-2,2-bis(p-chlorophenyl)ethane] has been used extensively as an organochlorine insecticide for the control of insects on agricultural crops and vector-borne diseases, such as typhus and malaria (14). DDT is highly persistent in the environment, with a reported half-life between 2-15 years, and is immobile in most soils. DDT was classified as a priority persistent organic pollutant by several different environmental regulatory agencies because of its toxicity, hydrophobicity and bioaccumulation $(7,9)$, and was banned in the 1970s from agricultural use because of its negative impact on wildlife and its ill effects on human health via the food chain. However, DDT continues to be used in some developing countries (primarily tropical countries) to control insect-borne diseases. Due to its extensive use and recalcitrance, numerous sites around the world are contaminated with DDT $(1,9,19)$, and many foodstuffs, including processed foods, have been shown to contain high levels of DDT residue $(2,7,12)$. Moreover, high levels of DDT and its metabolites have also 
been detected in human adipose tissue, blood plasma, liver, brain, placenta, and breast milk $(4,8,11,21)$. Therefore, the clean-up of DDT pollutants from contaminated sites is of great importance.

Routes of DDT loss from contaminated sites include runoff, volatilization, photolysis and biodegradation. However, microbial degradation of DDT is a promising and cost-effective method for treating DDT contamination. It was difficult for microorganisms to degrade DDT when it was used as the sole carbon source (3), but in the presence of an additional carbon source, DDT could be co-metabolized by many microorganisms under aerobic or anaerobic conditions $(3,13$, 24). Under anaerobic conditions, the metabolism of DDT was largely restricted to its alkyl chain (24), but under aerobic conditions, DDT underwent dioxygenation, followed by ring cleavage and the formation of p-chlorobenzoate $(16,17)$. It was reported that some metabolites, such as 1,1-dichloro-2,2-bis(pchlorophenyl)ethane (DDD) and 2,2-bis(p-chlorophenyl)-1,1dichlorethylene (DDE), produced during the co-metabolism of DDT, were more recalcitrant and toxic than the parent compound (9). However, few microorganisms have been reported to be capable of degrading DDT and its metabolites (DDD and DDE) simultaneously.

In this study, a bacterial strain, Pseudoxanthomonas sp. wax, which is capable of co-metabolizing DDT, DDD and DDE, and even some other organochlorine compounds, was isolated from a long-term DDT-polluted soil sample. The factors that influence the degradation activities of the wax strain were evaluated, and the bioremediation of DDTcontaminated soil by the wax strain was investigated.

\section{MATERIALS AND METHODS}

\section{Chemicals and media}

Analytical grade DDT (99\% pure), purchased from SigmaAldrich Chemical, MO, USA, was used as a standard. The technical grade DDT (70\% pure), pentachloronitrobenzene (PCNB) (95\% pure), cypermethrin (94\% pure), cyfluthrin (90\% pure), and bifenthrin (95\% pure) were provided by the
Yangnong Agricultural \& Chemical Co., Ltd, China. Chlorothalonil (98\% pure) was purchased from the Jiangyin Suli Fine Chemical Co., Ltd and $\gamma$-hexachlorocyclohexane (99\% pure) was purchased from the Tianjin Dagu Chemical Factory, China. Acetonitrile, acetone and dichloromethane were purchased from the Shanghai Chemical Reagent Co., Ltd, China. All other reagents used in this study were of analytical grade.

Luria-Bertani (LB) medium and minimal salt medium (MSM) (1.0 g NH $\mathrm{NO}_{3}, 1.5 \mathrm{~g} \mathrm{~K}_{2} \mathrm{HPO}_{4}, 0.5 \mathrm{~g} \mathrm{KH}_{2} \mathrm{PO}_{4}, 0.2 \mathrm{~g}$ $\mathrm{MgSO}_{4}$ and $1.0 \mathrm{~g} \mathrm{NaCl}$ per liter, $\mathrm{pH}$ 7.0) were used in this study. MSM, supplemented with $20 \mathrm{mg} \mathrm{l}^{-1}$ DDT, was then called DMM, and DMM, supplemented with $100 \mathrm{mg}^{-1}$ glucose was called GMM. Solid media plates were prepared by adding $1.5 \%(\mathrm{wt} / \mathrm{vol})$ agar.

\section{Strain isolation and characterization}

A soil sample $(2.0 \mathrm{~g})$ collected from the long-term DDT polluted soil in Yangzhou, China, was added to $100 \mathrm{ml}$ of GMM, and incubated at $30^{\circ} \mathrm{C}$ for 7 days in a rotary shaker at $150 \mathrm{rpm}$. Five milliliters of enriched cultures, showing degradation of DDT, were transferred to $100 \mathrm{ml}$ of fresh GMM. Three subcultures were performed before the final isolation of DDT-degrading strains. The final enriched culture was spread onto GMM plates. The different colonies that formed were isolated, and then tested for their DDT-degrading capabilities. One strain, designated as wax, possessed the highest degradation capacity of DDT, and was selected for further investigation.

The new isolate was identified based on its morphological, physiological and biochemical tests, with reference to Bergey's Manual of Determinative Bacteriology, combined with a $16 \mathrm{~S}$ rRNA gene sequence analysis. The cell morphology was examined by light microscopy (BH-2; Olympus) and transmission electron microscopy (TEM) (H-7650, Hitachi High-Technologies Corporation), using cells from an exponentially growing culture. The total genomic DNA of wax strain was prepared by high-salt precipitation (15). The universal primers, 5'-AGAGTTTGATCCTGGCTCAG-3' 
(Escherichia coli bases 8-27) and 5'-TACCTTGTTACGACT T-3' (E. coli bases 1,507-1,492), were used to amplify the $16 \mathrm{~S}$ rRNA gene (25). The purified PCR product was sequenced from both directions, using an ABI 377 sequencer (PerkinElmer Applied Biosystems, Foster City, CA). The 16S rRNA gene sequence $(1,503 \mathrm{bp})$ of wax strain was deposited in the GenBank database under the accession number FJ796079. Alignment of different $16 \mathrm{~S}$ rRNA gene sequences from GenBank was performed using Clustal X 1.8.3 (22), with the default settings. The phylogeny was analyzed with the MEGA version 3.0 software, and the distance was calculated using the Kimura 2 parameter distance model. The phylogenetic tree was built using the neighbor-joining method. Each dataset was bootstrapped 1,000 times (18).

\section{Analytical methods}

The cell density was monitored spectrophotometrically by measuring the absorbance at $600 \mathrm{~nm}$ with a SHIMADZU UVVis Recording spectrophotometer (Shimadzu UV-2410, Japan). DDT in the cultures was extracted with five times the volume of dichloromethane, and DDT in the soils was extracted with an equal volume of hexane and acetone $(1: 1, \mathrm{v} / \mathrm{v})$ by the supersonic extraction method. The organic extract was dried over anhydrous sodium sulfate, and then evaporated using a vacuum rotary evaporator at room temperature. The residual extract was dissolved in $5 \mathrm{ml}$ acetonitrile. Twenty microliters of the resulting solution was analyzed by reverse-phase high performance liquid chromatography (HPLC) (600 Controller, Rheodyne 7725i Manual injector, 2487 Dual 1 Absorbance Detector; Waters Co., Milford, MA). The separation column $(4.6 \mathrm{~mm} \times 250 \mathrm{~mm} \times 5 \mu \mathrm{m})$ was filled with Kromasil 1005C18. The mobile phase was acetonitrile/water (70:30, v/v), with a flow rate of $1.0 \mathrm{ml} \mathrm{min}{ }^{-1}$. The amount of chloride ion released from DDT was measured spectrophotometrically at $460 \mathrm{~nm}$ with mercuric thiocyanate and ferric ammonium sulfate, according to Iwasaki et al (5). The presence of DDD, DDE, PCNB, cypermethrin, cyfluthrin, bifenthrinat, chlorothalonil and $\gamma$-hexachlorocyclohexane was determined by HPLC, or gas chromatography (GC), as described previously $(10,23)$

\section{Degradation of DDT by wax strain in culture}

All aerobic batch cultivations were carried out in $250-\mathrm{ml}$ bottles, containing $100 \mathrm{ml}$ liquid culture, while being shaken at $150 \mathrm{rpm}$ at $30^{\circ} \mathrm{C}$. The wax strain was pre-cultured in $\mathrm{LB}$ medium for 18 hours, was centrifuged at 5,000 g for $10 \mathrm{~min}$, and the cell pellets were washed three times with fresh MSM. After adjusting the $\mathrm{OD}_{600 \mathrm{~nm}}$ of cell density to 1.0 , an inoculum $(5 \%, \mathrm{v} / \mathrm{v})$ was inoculated into liquid GMM medium unless otherwise stated. The medium, inoculated with heat-killed wax cells, was maintained as the control. All treatments were performed in triplicate. At different time periods, $2 \mathrm{ml}$ aliquots of the sample were removed for analysis. The degradation efficiency was determined by an estimation of the removal of DDT from the culture.

To investigate the effect of alternative carbon source on DDT biodegradation, $100 \mathrm{mg}^{-1}$ of glucose, succinate, starch, dextrin, or maltose, was added to DMM, respectively. To investigate the effect of the initial concentration of DDT on DDT biodegradation, GMM containing $5 \mathrm{mg} \mathrm{l}^{-1}, 20 \mathrm{mg} \mathrm{l}^{-1}, 50$ $\mathrm{mg} \mathrm{l}^{-1}$ and $100 \mathrm{mg} \mathrm{l}^{-1}$ DDT, were used. To investigate the effect of the initial $\mathrm{pH}$ value on DDT biodegradation, the $\mathrm{pH}$ values of the media were adjusted to 4.0, 5.0, 6.0, 7.0, 8.0, 9.0, and 10.0, respectively, by changing the potassium-phosphate buffer system. To investigate the effect of temperature on DDT biodegradation, the cultures were incubated at $10^{\circ} \mathrm{C}, 20^{\circ} \mathrm{C}$, $25^{\circ} \mathrm{C}, \quad 30^{\circ} \mathrm{C}, \quad 37^{\circ} \mathrm{C}, \quad 40^{\circ} \mathrm{C}$, and $45^{\circ} \mathrm{C}$, respectively. To investigate the effect of the initial inoculum size on DDT biodegradation, $1 \%, 5 \%$, and $10 \%(\mathrm{v} / \mathrm{v})$ of wax cells, respectively, were inoculated into GMM. To investigate the effect of aeration on DDT biodegradation, 250-ml bottles containing $30 \mathrm{ml}, 60 \mathrm{ml}, 100 \mathrm{ml}, 120 \mathrm{ml}, 150 \mathrm{ml}$, and $180 \mathrm{ml}$ of culture were used.

To study whether additional organochlorine compounds could also be degraded by wax strain, MSM media (containing $100 \mathrm{mg} \mathrm{l}^{-1}$ glucose) supplemented with DDD, DDE, PCNB, cypermethrin, cyfluthrin, bifenthrinat, chlorothalonil and $\gamma$ hexachlorocyclohexane, at final concentrations of $20 \mathrm{mg} \mathrm{l}^{-1}$, 
were used.

\section{Degradation of DDT in soil by wax strain}

Soil samples, from depths of 0 to $20 \mathrm{~cm}$, were taken of a fine sandy-loam soil in the Jiangsu province, with a $\mathrm{pH}$ value of 7.8. The soil samples were treated as described by Jiang et al (6). Subsamples (500 g) of sterile and non-sterile soil were amended with $20 \mathrm{mg} \mathrm{l}^{-1}$ DDT, and inoculated with wax cells at concentrations of $10^{8} \mathrm{CFU} \mathrm{g}^{-1}$ soil. The control soil samples were inoculated with heat-killed wax cells that were autoclaved at $121^{\circ} \mathrm{C}$ for $15 \mathrm{~min}$. The moisture of the soil was adjusted to $40 \%$ (wt/wt) during the experiment, and samples were incubated in the dark to preclude photolysis reactions (20). At periodic intervals, 10-g sub-samples were collected and analyzed immediately. All treatments were performed in triplicate.

\section{RESULTS}

\section{Isolation and characterization of the DDT-degrading wax strain}

A DDT-degrading strain, designated as wax, was isolated from long-term DDT polluted soil by an enrichment culture technique. The wax strain could degrade over $95 \%$ of the total DDT, at a concentration of $20 \mathrm{mg} \mathrm{l}^{-1}$, in GMM in 72 hours. The wax strain is a Gram-negative, rod-shaped $(0.3-0.5 \mu \mathrm{m} \times 1.2$ $3.0 \mu \mathrm{m})$, obligate aerobe that is motile via a polarly localized flagellum (Fig. 1). When growing on LB medium plates, the colonies of wax were yellow and convex with entire margins. The wax strain could grow at temperatures ranging from $10^{\circ} \mathrm{C}$ to $45^{\circ} \mathrm{C}$, and at $\mathrm{pH}$ values ranging from 5.0 to 10.0 . The optimal temperature and $\mathrm{pH}$ value for wax strain growth was $30^{\circ} \mathrm{C}$ and 7.0, respectively.

Biochemical tests showed that wax strain was oxidase and catalase positive, and urease, arginine dihydrolase, and indole production negative. The wax strain was unable to hydrolyze casein, cellulose, chitin, tween-40, tween-80 and starch; however, the wax strain could hydrolyze aesculin, tween-20 and tyrosine. The predominant isoprenoid quinone of wax strain was Q-8. Nitrite could not be reduced to nitrous oxide by the wax strain; however, nitrate could be reduced to the endproduct of nitrous oxide. The wax strain was resistant to streptomycin, nalidixic acid, kanamycin, ampicillin, gentamicin, fucidin and novobiocin. In addition, the wax strain could use glucose, maltose, starch and dextrin as carbon sources, and use yeast extract, peptone, urea, beef extract, $\mathrm{NH}_{4} \mathrm{NO}_{3},\left(\mathrm{NH}_{4}\right)_{2} \mathrm{SO}_{4}$ and $\mathrm{KNO}_{3}$ as nitrogen sources, and could grow in the presence of $3 \% \mathrm{NaCl}$. The phylogenetic tree of the 16S rRNA gene sequences is shown in Fig. 2. The wax strain is related to the Pseudoxanthomonas sp. lineage, and is closely clustered with two types of Pseudoxanthomonas strains, Pseudoxanthomonas suwonensis $4 \mathrm{M}^{\mathrm{T}}$ and Pseudoxanthomonas broegbernensis $\mathrm{B} 1616^{\mathrm{T}}$, with sequence similarity scores of $98.2 \%$ and $98.4 \%$, respectively. The result of the phylogenetic analysis was consistent with the morphological characteristics and the biochemical tests. Therefore, wax strain was determined to be a Pseudoxanthomonas sp.

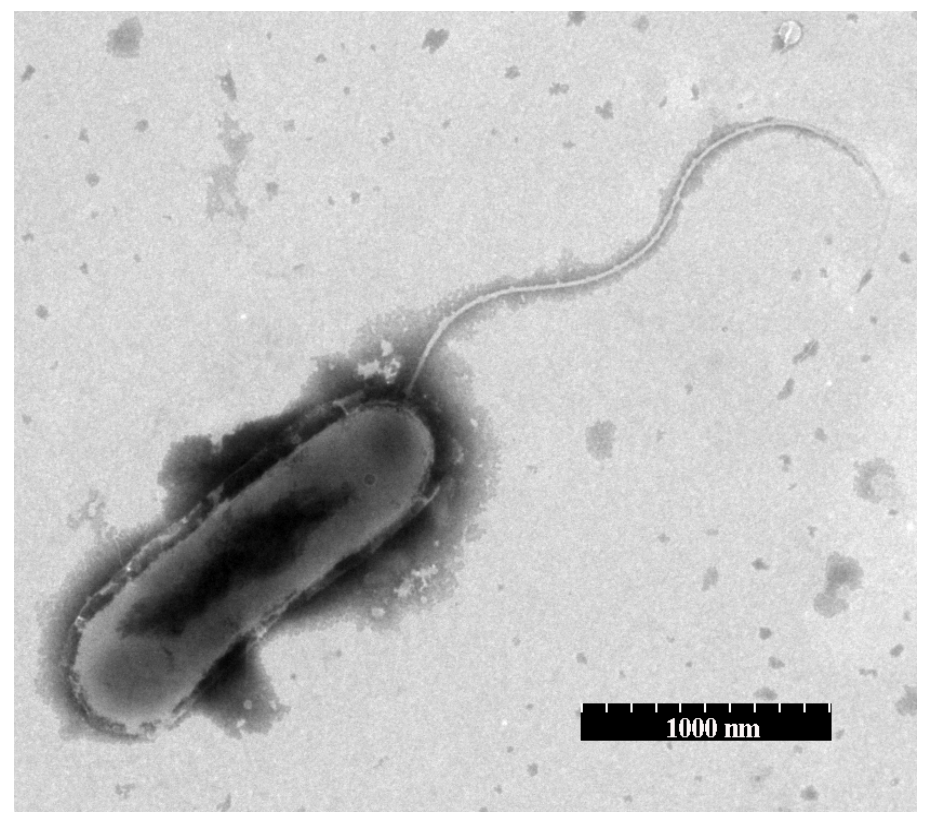

Figure 1. Micrograph of the strain wax under transmission electronic microscope showing its shape, size, and position of flagellum 


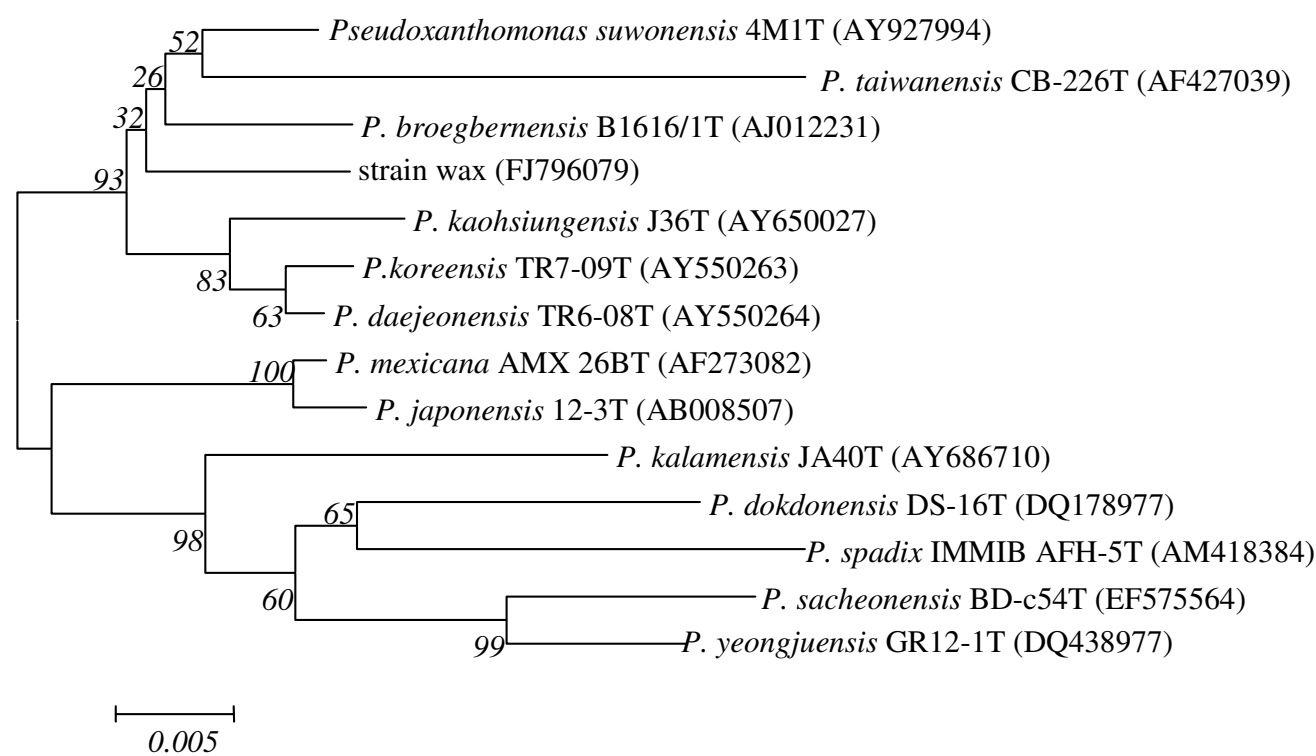

Figure 2. Phylogenetic tree based on the 16S rRNA gene sequences of the wax strain and related species. The GenBank accession number for each microorganism used in the analysis is shown in parentheses after the species name. The scale bar indicates 0.005 substitutions per nucleotide position. Bootstrap values, obtained with 1,000 resamplings, were indicated as percentages at all branches.

\section{Degradation of DDT by the wax strain in culture}

In GMM, the wax strain degraded $30.6 \%$ of the total DDT, at a concentration of $20 \mathrm{mg} \mathrm{l}^{-1}$ in 24 hours, while over $95 \%$ was degraded in 72 hours. However, in MSM, only 10.2\% of the total DDT was degraded in 72 hours (Fig. 3). These results demonstrate that the biodegradation of DDT by the wax strain was greatly affected by the alternative carbon source. When the wax strain grew in the presence of glucose as the carbon source, DDT was simultaneously co-metabolized with chloride ion released from DDT. It was found that other carbon sources, such as succinate, starch, dextrin and maltose, could also promote the biodegradation of DDT. Therefore, it is suitable for the wax strain to degrade DDT in naturally contaminated sites, where other carbon sources exist.

The wax strain could degrade DDT at a wide range of concentrations, even at very high concentrations. For instance, over $60 \%$ of the total DDT, at a concentration of $100 \mathrm{mg} \mathrm{l}^{-1}$, was degraded in 144 hours, and specifically $50 \mathrm{mg} \mathrm{l}^{-1}$ of DDT was nearly completely degraded in this time (Fig. 4). Even though a high concentration of DDT was toxic to the wax cells, and there was a delay in biodegradation when the initial concentration of DDT was over $50 \mathrm{mg} \mathrm{l}^{-1}$, the wax strain showed an uncommon tolerance of DDT at high concentrations.

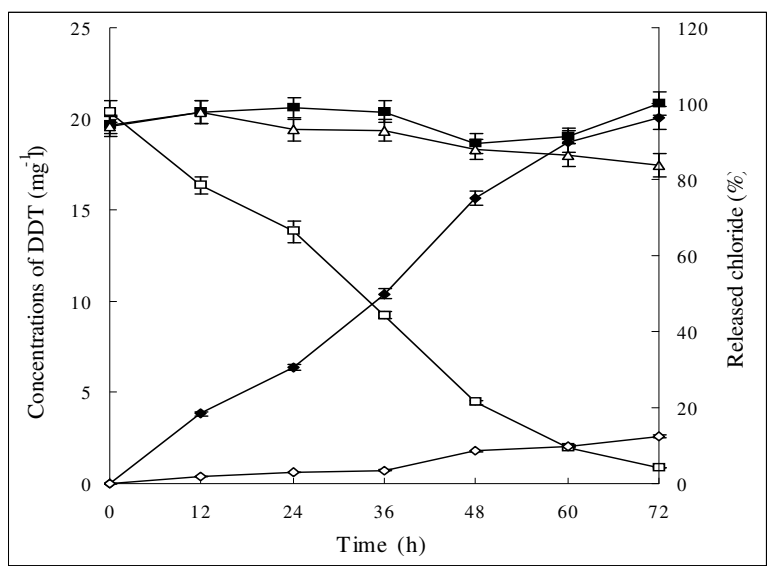

Figure 3. Degradation of DDT by Pseudoxanthomonas sp. wax in culture. $\square$, DDT control; $\square$, DDT biodegradation in DMM medium; $\square$, DDT biodegradation in GMM medium; $\square$, chloride released in DMM medium; $\square$, chloride released in GMM medium. Data are the means of results from triplicate experiments, and error bars indicate standard errors. Error bars that are not visible fall within the data point. 


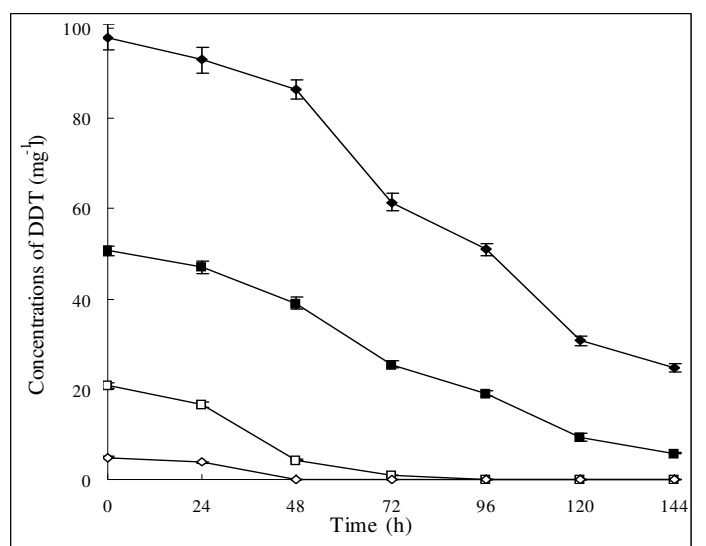

Figure 4. Effect of the initial DDT concentration on biodegradation of DDT by the wax strain in GMM. $\square, 100 \mathrm{mg}$ $\mathrm{l}^{-1} ; \mathbf{\square}, 50 \mathrm{mg} \mathrm{l}^{-1} ; \square, 20 \mathrm{mg} \mathrm{l}^{-1} ; \square, 5 \mathrm{mg} \mathrm{l}^{-1}$. Data are the means of results from triplicate experiments, and error bars indicate standard errors. Error bars that are not visible fall within the data point.

The wax strain could efficiently degrade DDT at temperatures ranging from 20 to $37^{\circ} \mathrm{C}$, with an optimal degradation temperature of $30^{\circ} \mathrm{C}$. The biodegradation of DDT was completely inhibited when the temperature was above $45^{\circ} \mathrm{C}$ or below $10^{\circ} \mathrm{C}$. The wax strain could rapidly degrade DDT, at initial $\mathrm{pH}$ values ranging from 7 to 9 , with an optimal $\mathrm{pH}$ value of 7.5; biodegradation of DDT was inhibited when the initial $\mathrm{pH}$ value was below 4.0. The degradation of DDT increased with an increase in inoculum size, for instance, when the inoculum size was $10 \%, 100 \mathrm{mg} \mathrm{l}^{-1}$ of DDT was degraded to a non-detectable level in 144 hours. The effect of aeration on DDT biodegradation was complex. Under significant aerobic conditions ( $30 \mathrm{ml}$ culture in the $250-\mathrm{ml}$ bottle), growth of the wax strain was optimal, however, the rate of DDT degradation was reduced. On the other hand, the highest rate of DDT degradation was found when the $250-\mathrm{ml}$ bottle contained 100 $\mathrm{ml}$ culture, albeit the growth of the wax strain was not the most optimal.

Interestingly, the wax strain had a broad degradingsubstrate range of organochlorine compounds. The degradation time course of some organochlorine compounds by the wax strain is presented in Fig. 5. It was found that $20 \mathrm{mg} \mathrm{l}^{-1} \mathrm{DDD}$ and DDE were nearly completely degraded in 144 hours, and that PCNB, cypermethrin, cyfluthrin and bifenthrinat were degraded to various extents. However, chlorothalonil and $\gamma$ hexachlorocyclohexane could not be degraded, and thus it was deduced that the side chains could also affect the biodegradation of organochlorine compounds.

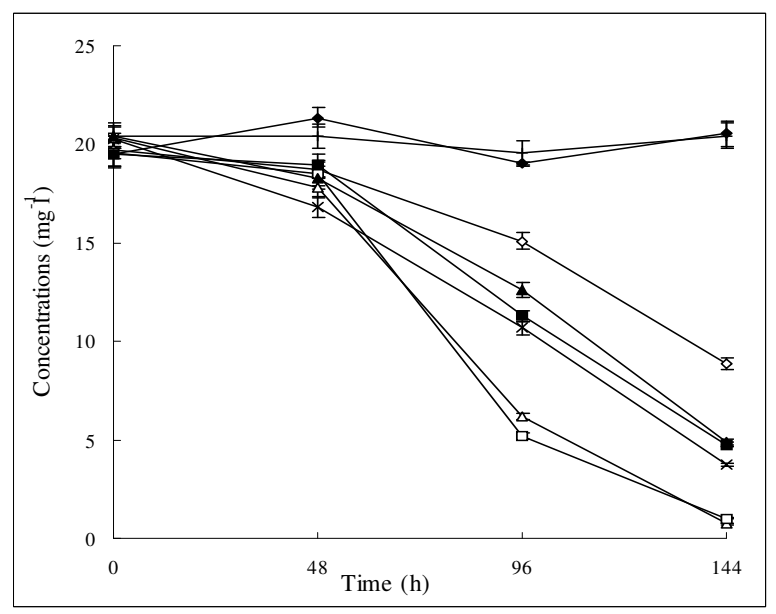

Figure 5. Degradation of different organochlorine compounds by the wax strain in liquid MSM supplemented with $100 \mathrm{mg}^{-1}$ glucose. $\square$, cyfluthrin; $\boldsymbol{\Delta}$, bifenthrinat; $\mathbf{a}$, cypermethrin; $\square$, DDD; $\square, \quad$ DDE; $\times, \quad$ PCNB; $\square$, chlorothalonil; $\square$, hexachlorocyclohexane. Data are the means of results from triplicate experiments, and error bars indicate standard errors. Error bars that are not visible fall within the data point.

\section{Degradation of DDT in soil by the wax strain}

It was found that $20 \mathrm{mg} \mathrm{kg}^{-1}$ of DDT was completely removed from both sterile and non-sterile soil samples by wax cells, at a concentration of $10^{8} \mathrm{CFU} \mathrm{g}^{-1}$, in 20 days (Fig. 6), while there was nearly no decline in the DDT concentration in the control soil samples, indicating that the wax cells were solely responsible for DDT removal. The high removal efficiency of DDT in non-sterile soil showed that the wax strain is potentially useful for the bioremediation of DDTcontaminated soil, even though there was competition between the indigenous populations and the inoculated strain. 


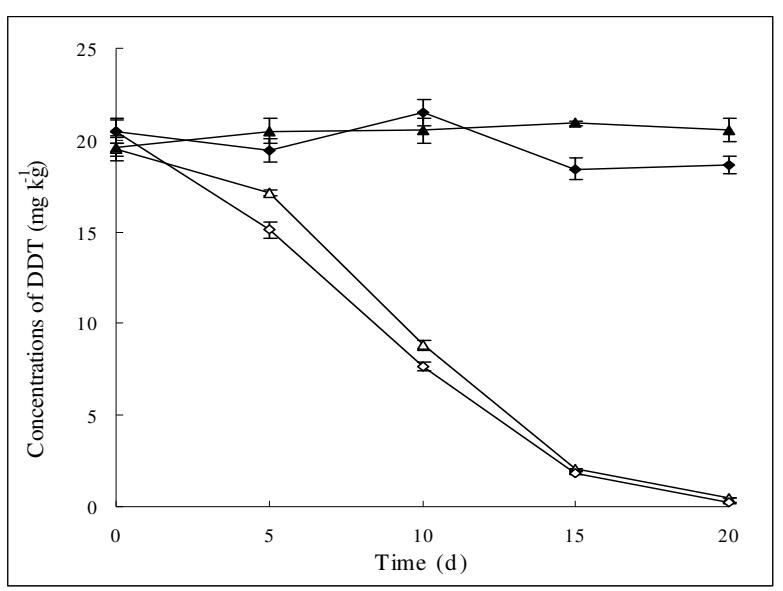

Figure 6. Degradation of DDT in sterile and non-sterile soils by the wax strain at a concentration of $10^{8} \mathrm{CFU} \mathrm{\textrm {g } ^ { - 1 }}$. $\boldsymbol{\Delta}$, DDT control in sterile soil; $\square$, DDT control in non-sterile soil; $\square$, DDT degradation in sterile soil; $\square$, DDT degradation in nonsterile soil. Data are the means of results from triplicate experiments, and error bars indicate standard errors. Error bars that are not visible fall within the data point.

\section{DISCUSSION}

DDT is highly persistent in the environment, and was banned in most of the advanced countries in the 1970s. Numerous sites around the world are contaminated with DDT. The microbial degradation of DDT shows a promising way to clean up the DDT-contaminated sites. Even though isolation of a microorganism capable of utilizing DDT as a sole carbon source is difficult, the co-metabolism of DDT by microorganisms with other carbon sources has been well documented, and the major metabolism products have been identified as DDD and DDE (1). To eliminate these contaminants from the environment, attempts have been made to isolate microorganisms that are capable of simultaneous degradation of DDT, DDD and DDE; however, few microorganisms are reported to have this capability.

In the present study, a DDT degrading strain, designated as wax, was isolated from long-term DDT-contaminated soils. The wax strain could degrade over $95 \%$ of total DDT at $20 \mathrm{mg}$ $1^{-1}$ in 72 hours in GMM. Based on the morphological, physiological and biochemical tests, combined with 16S rRNA gene sequence analysis, the wax strain was identified to be a Pseudoxanthomonas sp. of bacteria. Bacteria from the genus Pseudoxanthomonas are metabolically versatile, and this plays an important role in the biodegradation of organic xenoboitics. However, to our knowledge, this has been the first isolation of a strain of Pseudoxanthomonas species that could degrade DDT efficiently. Moreover, wax strain could not only degrade DDT, but could also degrade DDE, DDD, and other organochlorine compounds, which emphasizes the importance of the wax strain for the bioremediation of sites that are contaminated with multiple organochlorine pesticides. The wax strain could efficiently degrade DDT at temperatures ranging from 20 to $35^{\circ} \mathrm{C}$, and at initial $\mathrm{pH}$ values ranging from 7 to 9 , while the wax strain could even tolerate and degrade high concentrations of DDT (100 $\mathrm{mg} \mathrm{l}^{-1}$ ). To our knowledge, the wax strain had the highest degradation efficiency among all of the documented DDT-degrading bacteria. The inoculation of wax cells at $10^{8} \mathrm{CFU} \mathrm{g}^{-1}$ into both sterile and non-sterile soils, resulted in the complete removal of $20 \mathrm{mg} \mathrm{kg}^{-1}$ of DDT in 20 days. Due to broad substrate specificity, a strong degradation ability and adaptability to temperature variation, the wax strain is a promising candidate for the bioremediation of DDTcontaminated sites; although, the biochemical degradation pathway of DDT by wax strain has not yet been elucidated. Therefore, further research will be needed to clarify the degradation pathway and the properties of the key enzymes involved in the biodegradation of DDT.

\section{ACKNOWLEDGMENTS}

This work was supported by grants from the National Programs for High Technology Research and Development of China (2007AA10Z405) and the Key Technology R\&D Program of Jiangsu Province (BE2008669, BE2009670).

\section{REFERENCES}

1. Aislabie, J.M.; Richards, N.K.; Boul, H.L. (1997). Microbial degradation of DDT and its residues-a review. NZ. J. Agric. Res. 40(2), 269-282.

2. Appaiah, K.M. (1988). Insecticide residues in foods. A review of work done in India. Proceedings of Second International Food Convention. Mysore: CFTRL, 1988. 
3. Beunink, J.; Rehm, H.J. (1988). Synchronous anaerobic and aerobic degradation of DDT by an immobilized mixed culture system. Appl. Microbiol. Biotechnol. 29, 72-80.

4. Dale, W.E.; Copel, M.F.; Hayes, W.J. (1985). Chlorinated pesticides in the body fat of people of India. Bull. World Health Org. 33, 471-477.

5. Iwasaki, I.; Utsumi, S.; Ozawa, T. (1952). New colorimetric determination of chloride using mercuric thiocyanate and ferric ion. Bull. Chem. Soc. Japan. 25(3), 226-226.

6. Jiang, J.; Zhang, R.; Li, R.; Gu, J.; Li, S. (2007). Simultaneous biodegradation of methyl parathion and carbofuran by a genetically engineered microorganism constructed by mini-Tn5 transposon. Biodegradation. 18, 403-412.

7. Kannan, K.; Tanabe, S.; Ramesh, A.; Subramanian, A.; Tatsukawa, R. (1992). Persistent organochlorine residues in food stuffs from India and their implications on human dietary exposure. J. Agric. Food Chem. 40, $518-524$.

8. Kannan, K.; Tanabe, S.; Williams, R.J.; Tatsukawa, R. (1994). Persistent organochlorine residues in foodstuffs from Australia, Papua New Guinea and the Solomon Islands: Contamination levels and dietary exposure. Sci. Total. Environ. 153, 29-49.

9. Kelce, W.R.; Stone, C.R.; Laws, S.C.; Gray, L.E.; Kemppainen, J.A.; Wilson, E.M. (1995). Persistent DDT metabolite p, p-DDE is a potent androgen receptor antagonist. Nature. 375, 581-585.

10. Kim, Y.M. (2007). Cloning and characterization of bacterial gene involved in chlorothalonil-biotransformation. J. Nation. Fish University. 56(1), 153-160.

11. Kunhi, A.A.M.; Ajithkumar, P.V.; Ahamad, P.Y.A.; Chandrashekaraiah, D.H.; Reddy, N.S. 1995. A novel enrichment technique for the development of microbial consortia capable of degrading alpha-, beta-, gamma- and delta-isomers of hexachlorocyclohexane. Patent 2448/DEL/95 dt.

12. Lal, R.; Dhanraj, P.S.; Narayanarao, V.V.S. (1989) Residues of organochlorine insecticides in Delhi vegetables. Bull. Environ. Contam. Toxicol. 42, 45-49.

13. Masse, R.; Lalanne, D.; Messier, F.; Sylvestre, M. (1989). Characterization of new bacterial transformation products of 1,1,1trichloro-2,2-bis(4-chlorophenyl)ethane (DDT) by gas chromatography/mass spectrometry. Biomed. Environ. Mass. Spectrom.
$18,741-752$

14. Metcalf, R.L. (1973). A century of DDT. J. Agric. Food Chem. 21, 511519.

15. Miller, S.A.; Dykes, D.D.; Polesky, H.F. (1998). A simple salting out procedure for extracting DNA from human nucleated cells. Nucleic. Acids. Res. 16, 1215.

16. Nadeau, L.J.; Menn, F.M.; Breen, A.; Sayler, G.S. (1994). Aerobic degradation of 1,1,1-trichloro-2,2-bis(4-chlorophenyl) ethane(DDT) by Alcaligenes eutrophus A5. Appl. Environ. Microbiol. 60, 51-55.

17. Nadeau, L.J.; Sayler, G.S.; Spain, J.C. (1998). Oxidation of 1,1,1trichloro-2,2-bis(4-chlorophenyl) ethane (DDT) by Alcaligens eutrophus A5. Arch. Microbiol. 171, 44-49

18. Saitou, N.; Nei, M. (1987). The neighbor-joining method: a new method for reconstructing phylogenetic trees. Mol. Biol. Evol. 4, 406-425.

19. Simonich, S.L.; Hites, R.A. (1995). Global distribution of persistent organochlorine compounds. Science. 269,1851-1854.

20. Singh, B.K.; Walker, A.; Morgan, J.A.W.; Wright, D.J. (2003). Effects of soil $\mathrm{pH}$ on the biodegradation of chlorpyrifos and isolation of a chlorpyrifos-degrading bacterium. Appl. Environ. Microbiol. 69, 51985206.

21. Tanabe, S.; Gondaira, F.; Subramanian, A.; Ramesh, A.; Mohan, D.; Kumaran, P.; Venugopalan, V.K.; Tatsukawa, R. (1990). Specific pattern of persistent organochlorine residues in human breast milk from South India. J. Agric. Food Chem. 18, 899-903.

22. Thompson, J.D.; Gibson, T.J.; Plewniak, F.; Jeamougin, F.; Higgins, D.G. (1997). The Clustal_X windows interface: flexible strategies for multiple sequence alignment aided by quality analysis tools. Nucleic. Acids. Res. 25, 4876-4882.

23. Torres, R.M.; Grosset, C.; Alary, J. (2000). Liquid chromatographic analysis of PCNB and its metabolites in soil. Chromatographia. 51(9), 526-530.

24. Wedemeyer, G. (1967). Dechlorination of 1,1,1-trichloro-2,2-bis(pchlorophenyl)ethane by Aerobacter aerogenes. Appl. Microbiol. 15, 569574.

25. Wilson, K.H.; Blitchington, R.B.; Greene, R.C. (1990). Amplification of bacterial $16 \mathrm{~S}$ ribosomal DNA with polymerase chain reaction. J. Clin. Microbiol. 28, 1942-1946. 